\title{
CÓDICES MISCELÁNEOS DE AGRONOMÍA ANDALUSÍ
}

\author{
Julia María CARABAZA \\ Universidad de Sevilla \\ Expiración GARCía \\ CSIC, Granada
}

\section{INTRODUCCIÓN}

Uno de los principales obstáculos que se presentan, a la hora de estudiar los textos agronómicos andalusíes, es el hecho de que la mayor parte de ellos se insertan en manuscritos de carácter misceláneo que, por lo general, aparecen adscritos a un solo autor. Este hecho ha originado una serie de atribuciones erróneas que han ido manteniéndose aunque, por fortuna, en los últimos años se han llevado a cabo diversos trabajos en los que las autorías han comenzado a aclararse y a delimitarse ${ }^{1}$. Igualmente, dicho carácter misceláneo ha impedido tener una visión clara de las aportaciones a este campo de la ciencia que corresponden a cada uno de los agrónomos hispanoárabes, y ha favorecido el que se hagan ediciones bajo falsas autorías hasta hace relativamente pocos años.

Dado que en otras disciplinas tradicionales como la historia, la literatura, la jurisprudencia o la filosofía no ocurre con frecuencia este fenómeno y que, incluso, en el mismo apartado de historia de la ciencia, como por ejemplo en la medicina, tampoco es habitual que los textos se encabecen con un autor erróneo, o que diversas obras se enlacen entre sí sin delimitar sus respectivas procedencias, debemos preguntarnos cuáles son las causas de este hecho. ¿Por qué precisamente en los manuscritos de agricultura andalusíes hay tantos ejemplos de atribuciones incorrectas, resultantes de que se nombre a un solo autor cuando, en realidad, el códice contiene más de una obra, o de que se citen varias autorías pero no todas las correspondientes a los textos insertos en el manuscrito en cuestión, o de que aparezcan como autores los nombres de copistas y de personas que elaboraron algunos resúmenes o, simplemente, se adscriban a autores falsos?

Consideramos que existen una serie de factores que pueden desembocar en algunas posibles respuestas a estos interrogantes. En primer lugar, hay que

${ }^{1}$ Cf. García Sánchez, E., "Problemática en torno a la autoría de algunas obras agronómicas andalusíes", Homenaje al Prof. Darío Cabanelas Rodríguez, o.f.m., con motivo de su LXX aniversario. Granada, 1987, 333-41; Carabaza Bravo, J. M., "La edición jordana de al-Muqni de Ibn Haŷŷâŷ. Problemas en torno a su autoría”, Al-Qantara XI (1990), 71-81. 
destacar el que los geóponos solamente son mencionados en las fuentes históricobiográficas cuando, aparte de su labor agronómica, desarrollan otras actividades de mayor relevancia social o intelectual. Así, Ibn Wāfid (Toledo, s. XI) es nombrado por Ibn al-Abbār, además de como agrónomo teórico y práctico (compuso un Maŷmū‘ fī l-filāha y se encargó de la huerta de al-Ma'mūn de Toledo), como médico y hombre versado en jurisprudencia ${ }^{2}$. En el caso de alTignarī (Granada, ss. XI-XII), Ibn Bassām lo cita tan sólo como excelente poeta pero Ibn al-Jậīb, además de esta faceta, menciona su actividad geopónica como autor de un tratado de agricultura ${ }^{3}$. De Ibn Luyūn (Almería, s. XIV), aparte de consignarse su labor agronómica, se dice que fue filósofo, jurista, matemático y mediocre poeta ${ }^{4}$. Las menciones del geópono Ibn Haŷŷâŷ (Sevilla, s. XI) poseen un carácter particular: a pesar de que sabemos que escribió un tratado agrícola, las fuentes biográficas únicamente le nombran como waz $\bar{\imath}$, jat $\grave{\imath b}$ y $a d \imath^{5} b^{5}$.

Un caso diferente es el de Ibn Bașșāl (Toledo, s. XI) e Ibn al-'Awwām (Sevilla, ss. XII-XIII) ya que, al primero, se le nombra tan sólo como autor de un tratado de agricultura ${ }^{6}$, y al segundo se le califica como simple compilador de la Filaha Nabatiyy $a^{7}$, sin ninguna referencia, por tanto, a otras actividades propias de ambos autores. En cuanto al resto de los geóponos —el Anónimo andalusí (ss. $\mathrm{X}$-XI) y Abū l-Jayr (Sevilla, ss. XI-XII) - , no son mencionados en absoluto por las fuentes histórico-biográficas, seguramente porque no destacarían en ningún otro plano salvo en el de la agronomía .

Esta escasez de datos facilitados por las fuentes está íntimamente relacionada con un segundo elemento que hemos de tener en cuenta: la agronomía debía ser considerada como una técnica y, como tal, no gozaría del mismo prestigio y valor socio-cultural que las ciencias entendidas en el más amplio sentido del término

\footnotetext{
${ }^{2}$ Ibn al-Abbār, al-Takmila, ed. F. Codera. Madrid, Bibliotheca Arabico-Hispana V-VI, 1886-89, VI, p. 551. Por otra parte, su contemporáneo el cadí toledano Șā‘id únicamente alude a su faceta como médico. Șā‘id al-Andalusī, Kitāb Țabaqāt al-umam (Livre des Catégories des Nations), trad. francesa por R. Blachère. Paris, 1935, 150-1.

3 Ibn Bassām, al-Dֵajīra fĭmahāsin ahl al-ŷaz ìra, ed. I. 'Abbās. Bayrūt, 1398/1978, I/2, 805-8; Ibn al-Jạ̣īb, al-Ihạ̄ta fi ajbār Garnạ̈ta, ed. M.A. 'Inān. Al-Qāhira, 1394/1974, II, 282-4.

${ }^{4}$ Ibn al-Qāḍ̄i, Durrat al-hiyâal, ed. I.S. Allouche. Al-Ribāit, 1939, II, 467-70; al-Maqqarī, Nafh alt tib, ed. I., 'Abbās. Bayrūt, 1968, V, 543-4 y 603-5.

5 Ibn Bassām, al-Dajīira, I, p. 25 y III, p. 238, nota 1; Ibn Sa'īd, al-Mugrib fíhulà l-Magrib, ed. Š. Dayf. Al-Qāhira, 1978, $3^{\text {a }}$ ed., I, p. 256, n. 179.

${ }^{6}$ Ibn Sa‘īd, al-Mugrib, II, p. 9; al-Maqqarī, Nafh al-t tib, III, p. 151.

${ }^{7}$ Ibn Jaldūn, al-Muqaddima, ed. M. Quatremère. Paris, 1858, III, 120-1; trad. francesa M. de Slane. Paris, 1868, III, 165-6.
} 
árabe 'ulūm ${ }^{8}$. Lógicamente, esta consideración no era compartida por los propios geóponos quienes ven en la agricultura bien un arte (fann), un oficio (sinā'a), o una verdadera ciencia ( $i l m$ ). Este último sentido es enfatizado por Abū 1-Jayr, quien nos dice: «la agricultura es una ciencia bien fundada, una gracia divina y una enorme recompensa»" Igualmente, en el plano económico ${ }^{10}$ y en el religioso ${ }^{11}$, se destaca la importancia de esta actividad para el bienestar material y espiritual del ser humano. No obstante, ninguna de estas favorables opiniones influyeron en los biógrafos árabes que, como ya hemos dicho, apenas se detuvieron en el quehacer agronómico de los autores consignados.

En tercer lugar, podemos observar el hecho de que algunos tratados agrícolas andalusíes fueron objeto de resúmenes bien avanzado el siglo XIII, a excepción del de Ibn Bașāāl que, con toda seguridad, se compendió en vida del autor como lo muestran sus propias palabras recogidas en la Zuhrat al-bustān de al-Tignarī: "Se han hecho en esta obra [Kitāb al-Filäha] algunas cosas contra mi voluntad, pues cada uno la ha arreglado a la medida de su capricho» ${ }^{12}$. Es más, el caso de este agrónomo toledano es también único en el sentido de que circularon conjuntamente, durante al menos dos siglos, tanto el original como el resumen de su obra, y prueba de ello son las citas que Ibn al-'Awwām recoge de ambos textos ${ }^{13}$, así como la traducción castellana alfonsí de Ibn Bașạāl que, en algunos pasajes, parte del original andalusí de mayor amplitud que el resumen que ha llegado hasta nosotros $^{14}$. En esta ocasión, por tanto, hemos de dar la razón a B. Attié cuando

\footnotetext{
${ }^{8}$ Para una visión muy resumida de las distintas clasificaciones de las ciencias véase Vernet, J., $\mathrm{La}$ cultura hispanoárabe en Oriente y Occidente. Barcelona, 1978, pp. 33-5; Samsó, J., Las ciencias de los antiguos en al-Andalus. Madrid, 1992, p. 16.

${ }^{9}$ Abū l-Jayr, Kitäb al-Filặa. Tratado de agricultura, introd., ed., trad. e índices J. M. Carabaza. Madrid, 1991, 343 y 365.

${ }^{10}$ Cf. las conocidas palabras de Ibn 'Abdūn que hace a la agricultura sinónimo de base de la civilización. García Gómez, E. y Lévi-Provençal, E., Sevilla a comienzos del siglo XI. El tratado de Ibn 'Abdūn. Sevilla, 1981 (reimp. 1948), 42-3.

${ }^{11}$ Véanse los variados hadices y aleyas que insisten en la importancia de la agricultura para la vida del hombre en García Sánchez, E., “Agricultura y legislación islámica: el prólogo del Kitäb Zuhrat albustān de al-Tignarī”, Ciencias de la Naturaleza en al-Andalus. Textos y Estudios (CNA) I. Granada, (1990), 179-93.

${ }^{12}$ Al-Tignarī, Kitāb Zuhrat al-bustān wa-nuzhat al-ad̆ān, manuscrito n. ${ }^{\circ} 4$ del Archivo Municipal de Córdoba, folios 62v y 63r, y manuscrito n. 2163 de la Biblioteca Nacional de Argel, folios $65 \mathrm{r}$ y $65 \mathrm{v}$.

${ }^{13}$ Cf. Ibn al-'Awwām, Libro de agricultura, ed. y trad. J.-A. Banqueri. Madrid, 1802 (ed. facsímil con estudio preliminar y notas de J. E. Hernández Bermejo y E. García Sánchez. Madrid, 1988), I, 530 y 547 , II, 46, 55-8, 102, 105, 108, $121-2$ y 350 , entre otras.

${ }^{14}$ Véanse, entre otros, los capítulos titulados «La XXXVIII partida es de melesinar el çidrial cuando adolesçe el çidrial e fasen sus fojas amarillas, melesinan las desta guisa", "La XLII partida es de llantar el alfesact o alfónsigo dotra guisa", "La XLVIII partida es de senbrar las castannas», "La LI partida es
} 
dice: «les abrégés voyaient le jour presque inmédiatement après la publication du traité original! " ${ }^{15}$, pero consideramos que el resto de los resúmenes se elaborarían a partir del siglo XIV. De hecho, entre los autores citados en el prólogo del resumen de la obra de al-Ṭignarī, tenemos a Ibn al-Ḥâŷib (m. 570/1249) y alNawawī (m. 676/1277) ${ }^{16}$. Igualmente, el agrónomo almeriense Ibn Luyūn maneja el tratado original de al-Tiignarī y expone en su urŷ̄zza las partes de que constaba: "contiene doce tratados (número igual al de los signos del Zodiaco y al de los meses del año) y trescientos sesenta capítulos (tantos como grados tiene la circunferencia)" ${ }^{17}$.

Otra prueba de lo que acabamos de decir la constituye el que el autor anónimo sirio del Miftāh al-răha li-ahl al-filăḥa (siglo XIV) utilizó, para elaborar su tratado, la obra completa del toledano Ibn Bașsāl, ya que en repetidas ocasiones las citas que hace de éste son más extensas y claras que el resumen llegado a nuestros días ${ }^{18}$.

Si tenemos en cuenta que, en el siglo XIV, las tropas cristianas habían dejado reducido el territorio andalusí a los confines del reino nazarí y que, por tanto, la cultura arabo-islámica se veía amenazada, es lógico que se intentara preservar el patrimonio hasta entonces acumulado y, puesto que la creatividad se había agotado tanto en éste como en otros campos del saber, sólo era posible comentar o resumir las aportaciones anteriores (tal como sucedería, siglos más tarde, durante el dominio otomano en el mundo árabe). De ahí que se produjeran los resúmenes de las obras agrícolas ya mencionados, e incluso extractos de resúmenes.

También en este aspecto el tratado de Ibn Haŷŷây constituye un caso particular ya que, si bien en el siglo XIII Ibn al-'Awwām maneja el original completo de su obra, todas las copias conocidas en la actualidad de dicho texto recogen unos determinados fragmentos (siempre los mismos) concernientes al cultivo del olivo, de la vid, de la higuera, plantas hortenses y aromáticas. Estos fragmentos, al ser cotejados con el Kitāb al-Filäha de Ibn al-'Awwām,

de senbrar el çedeharec que disen arbol de parayso", y "La VIII partida es de senbrar el lino en rregantio". Ibn Bașșā, Libro de agricultura, ed. y trad. J. M. Millás Vallicrosa y M. 'Azīmān. Tetuán, 1955 (ed. facsímil con estudio preliminar e índices de E. García Sánchez y J. E. Hernández Bermejo. Sevilla, 1995), 98, 101, 105, 107 y 146.

15 Attié, B., "L'ordre chronologique probable des sources directes d'Ibn al-'Awwām", Al-Qantara III (1982), p. 304.

${ }^{16}$ Cf. García Sánchez, E., "Agricultura y legislación islámica», p. 183.

${ }^{17}$ Ibn Luyūn, Kitäb Ibdä’ al-malăha wa-inhä’ al-raŷăha fī ușül șinä'at al-filäha, ed. y trad. J. Eguaras Ibáñez. Granada, 1988 (reimp. 1975), 61 y 204.

${ }^{18}$ Miftạn al-rạha li-ahl al-filạ̣a, ed. M.'I. Șạihiyya e I. Șudqī al-“Amd. Kuwayt, 1984, 107, 120, 165,194 y 207 , entre otras. 
demuestran que están extractados del original y, por tanto, no pueden considerarse como un resumen del mismo.

En cuarto y último lugar, nos encontramos con que son muy escasas las citas que hacen los geóponos andalusíes de los compatriotas que vivieron en siglos inmediatamente anteriores y posteriores a ellos, si exceptuamos el caso de Ibn al'Awwām que sí recoge las enseñanzas de todos los agrónomos que le precedieron, de al-Tignarī que alude a Ibn Bașșāl, y de Ibn Luyūn que menciona en repetidas ocasiones a estos dos últimos. Esta circunstancia no resulta del todo extraña, si tenemos en cuenta que una buena parte de los tratados agrícolas andalusíes se escribieron en fechas muy cercanas entre sí. De este modo, Ibn Wāfid, Ibn Haŷŷâŷ, Ibn Baș̣āl, Abū l-Jayr y al-Ṭignarī redactaron sus obras con una diferencia de apenas cincuenta años que irían desde mediados del siglo XI hasta principios del XII. Dado que los cauces de difusión de esta época eran muy reducidos y de lento desarrollo, los agrónomos seguramente intercambiarían informaciones entre $\mathrm{si}^{19}$ pero no habrían tenido en sus manos el texto redactado de las diferentes obras. Únicamente al-Ṭignarī, el más tardío de los últimos autores mencionados, cita de forma expresa el tratado de Ibn Bașsāl, e igualmente nombra a Ibn Wāfid pero no como autor de una obra agrícola sino de carácter farmacológico ${ }^{20}$. Lo que sí ignoramos aún es la razón por la cual el nombre de Ibn Wāfid no aparece en el tratado de Ibn al-'Awwām, aunque sí recoge diversos pasajes de su obra agrícola.

Una vez expuestos los factores mencionados más arriba, vamos a retomar el tema de las erróneas atribuciones de los manușcritos agrícolas andalusíes, tema al que aquéllos podían dar respuesta. Como ya hemos indicado, la agricultura no se consideraba una ciencia en sí misma y, por tanto, los geóponos andalusíes apenas fueron objeto de interés para los biógrafos. Teniendo en cuenta el nivel cultural en que tanto unos como otros se movían, podemos deducir que la incidencia de las obras agronómicas en la sociedad de su tiempo fue prácticamente inexistente, y que los nombres de sus autores apenas circularon en dicha sociedad. Así pues, no debe extrañarnos que se diera una gran confusión de autorías e incluso que aparecieran algunas falsas en los distintos códices que se nos han conservado.

\footnotetext{
${ }^{19}$ Nos consta que casi todos los autores del siglo XI pasaron en Sevilla parte de su vida y en ella se formaron y desarrollaron sus actividades agronómicas. $C f$. García Sánchez, E., «El botánico anónimo sevillano y su relación con la escuela agronómica andalusín, CNA III. Granada, (1994), 193-210.

${ }^{20}$ En efecto, encontramos citas del Kitab al-Adwiya al-mufrada, aunque no siempre se explicita su título, entre otros, en los folios siguientes: 39r, 106r y 110v del manuscrito n. 2163 de la Biblioteca Nacional de Argel. Por otra parte, en notas marginales del códice original de la urŷūza de Ibn Luyūn (ms. n. ${ }^{\circ} 14$ de la Escuela de Estudios Árabes de Granada) también aparece, además de dos breves fragmentos de esta obra de Ibn Wāfid (fols. 36v y 46v), una cita de su tratado agrícola (fol. 8r).
} 
El hecho de que varios tratados se escribieran en un período de cincuenta años, y además en el mismo entorno geográfico como fue la capital hispalense, también contribuyó sin duda a que los textos se mezclaran sin tener aún una autoría bien definida. Si a ello añadimos que después circularon resúmenes de algunos tratados agrícolas, es lógico que se diluyeran aún más los contenidos, con sus correspondientes autores, de dichos tratados, y que se formara el corpus del que habla E. García Gómez ${ }^{21}$. Este profesor lo denomina concretamente "corpus de agricultura sevillana", adjetivo este que puede llevar a confusión pues, si bien gran parte de los geóponos del siglo XI se formaron en Sevilla, dicho corpus está constituido por textos de autores de variada procedencia (Sevilla, Toledo, Granada...), por lo que consideramos sería más correcto definirlo como «corpus de agricultura andalusí». Esta mezcla de los diversos tratados de agricultura - a la que, sin duda alguna, llevó la intención del uso práctico de los mismos- la apreciamos ya en Ibn al-'Awwām, y se reitera en los códices que conocemos de carácter misceláneo, como vamos a ver a continuación.

\section{MANUSCRITOS MISCELÁNEOS}

Analizamos en este apartado, de forma breve, los diferentes códices misceláneos en los que se insertan los tratados agrícolas andalusíes, centrándonos especialmente en las diferentes autorías que aparecen en cada uno de ellos, y en las que se les han atribuido más tarde. Seguiremos en nuestro estudio el orden alfabético de las ciudades en cuyas bibliotecas se encuentran los diversos manuscritos, comenzando por los fondos existentes en los países árabes, y siguiendo por los presentes en las bibliotecas europeas ${ }^{22}$.

21 Cf. García Gómez, E., "Traducciones alfonsíes de agricultura árabe», Boletín de la Real Academia de la Historia CLXXXI, cuad. III (sept. 1984), 394-5.

${ }^{22}$ Es preciso aclarar que, además de estos códices de carácter misceláneo, los tratados agrícolas andalusíes también se recogen en otros manuscritos que carecen de dicho carácter, y de los que ya hemos hablado en trabajos anteriores. $C f$., por ejemplo, Carabaza Bravo, J.M., García Sánchez, E. y Llavero Ruiz, E., "Obras manuscritas de los geóponos andalusíes (siglos X-XII)", Homenaje al Prof. Jacinto Bosch Vilá, Granada, 1991, II, 1115-32. 


\section{BIBLIOTECA NACIONAL DE ARGEL}

1. Ms. número $1550^{23}$

El manuscrito consta de un total de 200 folios numerados. Aunque es difícil precisarlo con absoluta seguridad, parece que intervinieron varios copistas en él; no obstante, no se conoce la identidad de ninguno, aunque sí la fecha en que fue realizada la copia, el año $1197 \mathrm{H}$., correspondiente al 1782-3, según consta en el folio 151v.

El apartado relativo a la agronomía andalusi $i^{24}$ ocupa los folios $154 \mathrm{v}$ al $193 \mathrm{v}$ y comprende dos obras fragmentarias, cada una con su respectivo explicit. En el primero de éstos (fol. 180r) se lee "fin del Kitāb al-Filāha de Abū 1-Qāsim b. "Abbās al-Nahrāwī", autor que ha sido objeto de diversas y controvertidas opiniones acerca de su verdadera identidad. La primera - por otra parte lógica, dado que sólo implica un cambio de nūn por zāy en la nisba- es la que lo identifica con el conocido médico cordobés al-Zahrāwī y fue propuesta por $\mathbf{M}$. Ullmann $^{25}$. Dicha opinión ha sido duramente rebatida por B. Attié, para quien alNahrāwī es un autor anónimo andalusí, aunque cristiano, ya que Ibn al-'Awwām lo cita en la tercera sección de su tratado, dedicada exclusivamente a los andalusíes ("Ibn al-'Awwām cite ce traité dans la troisième section, consacrée uniquement aux andalous nommés et anonymes" $)^{26}$, conclusión esta que no podemos aceptar, dada su total inconsistencia. Más tarde, por la correspondencia del texto de este manuscrito con el de otros códices, se afirmaría que estos folios (154v-180r) pertenecen a Ibn Wāfid.

El contenido de la segunda obra (fols. 180v-193v), en cuyo explicit no se cita autor alguno, es un resumen anónimo -o fragmentos de dicho resumen- del Kitāb al-Filāha de Ibn al- 'Awwām" ${ }^{27}$ y coincide con el de los folios 176v-186v del códice n. ${ }^{\circ} 5754$ de la Biblioteca Nacional de Francia (del que hablaremos más adelante). 426-7.

${ }^{23}$ Fagnan, E., Catalogue des manuscrits arabes de la Bibliothèque Nationale d'Alger. Paris, 1893,

${ }^{24}$ Contiene también el códice, al inicio y al final, fragmentos de diversas obras de temática ajena a la agricultura. Lo inicia un compendio de la obra geográfica de al-Idrīsī titulada al-Kalām 'alà șūrat al-ard (fols. $1 \mathrm{v}-151 \mathrm{v}$ ), al que siguen unos folios en blanco (152r-154r). Al final de la última obra de tema agrícola vuelven a aparecer unos folios (194r-196r) en blanco, para acabar el códice con un relato sobre Dū l-Qarnayn, es decir, Alejandro Magno (fols. 196v-200r).

${ }^{25}$ Ullmann, M., Die Natur-und Geheimwissenschaften im Islam. Leyde, 1972, p. 443.

26 Attié, B., "L'ordre chronologique", 306-7.

27 Attié, B., "Les manuscrits agricoles de la Bibliothèque Nationale de Paris", Hespéris-Tamuda X (1969), p. 261. 


\section{BIBLIOTECA GENERAL Y ARCHIVOS DE RABAT}

1. Ms. número $617 \hat{y}^{28}$.

Códice de 510 páginas en el que no aparece ningún nombre de posible copista, pero en el que sí constan dos fechas diferentes; la primera, que se encuentra en la página 509, corresponde al manuscrito del que parte el códice que ahora nos ocupa: 21 de muharram del 970, es decir, 20 de septiembre de 1562, y la segunda, sita en la página 510, es la fecha en la que se elabora el presente manuscrito de Rabat: 25 de šawwäl de 1278, esto es, 25 de abril de 1862.

El único agrónomo andalusí citado en este códice es Ibn Haŷŷâŷ, cuyo nombre aparece en la página 414 , hecho por el cual todo el texto se le atribuye en el catálogo correspondiente. No obstante, contiene cuatro tratados agrícolas hispanoárabes: el de al-Ṭignarī (pp. 1-269), el de Ibn Bașșāl (pp. 270-413), el de Ibn Wāfid (pp. 414-478) y, finalmente, el de Ibn Haŷŷâŷ (pp. 478-510). Si bien nosotros defendemos las dos últimas autorías ${ }^{29}$, los editores de la obra titulada alMuqni ‘ $f i ̄ l$-filahha siguieron, al utilizar este manuscrito, la autoría presente en la página 414 y, por tanto, toman como obra de Ibn Haŷŷâŷ las páginas 414 a $510^{30}$.

\section{Ms. número $1410 \mathrm{D}^{31}$}

En el catálogo de Allouche y Regragui, este códice está atribuido totalmente a Ibn Hậyyâŷy, cuyo nombre aparece en el último folio de la copia. Sin embargo, es uno de los misceláneos de agricultura andalusí que presenta una mayor diversidad de textos - siete-, con un total de 216 folios.

El nombre del único copista del códice, Muḥammad b. al-Ḥâŷy al-Fātimī alRaŷrāŷî, aparece en el folio 98r. La copia data del 1306 de la Hégira -equivalente al 1889 d.C.- como figura en el explicit de dos de las obras. También se indica (fol. $215 \mathrm{v}$ ) la fecha del códice que sirvió de base a la última

${ }^{28}$ Este códice, de la colección Ŷallāwī, no está registrado en ninguno de los catálogos de la Biblioteca General y Archivos de Rabat existentes en la Escuela de Estudios Árabes de Granada, y se consultó en su día en dicha biblioteca.

${ }^{29} C f$., entre otros trabajos, Carabaza, J. M., Ahmad b. Muhammad b. Hậ̂ŷŷy al-Išbit ĭ: al-Muqni * fil-filaha. Introducción, estudio y traducción, con glosario (Tesis Doctoral ed. microfichas). Granada, 1988, I, pp. 114-175, y "Una versión catalana de un tratado agrícola andalusí”, CNA III, 169-92.

${ }^{30}$ Ibn Haŷŷây, al-Muqni' fĭl-filah̆a, ed. Ș. Ŷarrār y Ŷ. Abū Șafiyya, 'Ammān, 1982.

31 Allouche, I. S. et Regragui, A., Catalogue des manuscrits arabes de Rabat (Bibliothèque Générale et Archives du Maroc), deuxième série (1921-1953), Rabat, 1958, II, p. 274. 
obra agrícola de este misceláneo, 21 de muharram del año 970 (20 de septiembre de 1562), fecha que coincide con la del manuscrito n. 5013 de la Biblioteca Nacional de Francia, que sirvió de base a ésta y a otras copias.

Lo inicia el tratado de Ibn Bașsāl (fols. 1v-98r), aunque no figura su nombre ni el de la obra. Tras unos folios en blanco le siguen otros (101r-105r) referidos a un calendario de carácter astronómico y meteorológico, de autor anónimo. En tercer lugar (fols. 105v-130v) se encuentra, incompleto, el resumen del Kitäb Zuhrat al-bustān de al-Țignarī, sin ser citado ni uno ni otro. Le siguen (fols. 130v133v) unos excerpta del tratado agrícola de Abū l-Jayr, cuyo nombre es citado. Los folios 134r-139v están tomados de la Filäha Nabatiyya, tal como reza en el folio 135v. Ocupan el sexto lugar (fols. 140r-154v) unos extractos de Ibn al'Awwām, para acabar el códice con la obra de Ibn Wāfid (fols. 157r-194r) y la de Ibn Ḥâyyāây (fols. 194r-216r).

\section{BIBLIOTECA REAL DE RABAT}

1. Ms. número $69^{32}$

En este códice de 103 páginas hallamos también el nombre del copista de la obra: Muḥammad b. 'Abd Allāh al-Sūsī al-Hilālī. Del mismo modo, podemos observar tanto la fecha del manuscrito del que parte nuestro número 69 como la propia fecha de redacción de éste: en cuanto a la primera (p. 102), es el 11 de muharram del 1251 correspondiente al 9 de mayo de 1835, y la segunda (p. 103) es mediados de $\underline{d} \bar{u} l$-hîy $\hat{y} a$ de 1264 , equivalente a mediados de noviembre de 1848.

En el manuscrito no se nombra a ningún autor, pero en el catálogo de la Biblioteca Real ya anotado, se adscribe la totalidad del texto a Ibn Hạŷyâŷ, autoría que también mantienen los editores jordanos de al-Muqni ' (quienes utilizaron este códice junto con el 617 ŷ de la Biblioteca General y Archivos de Rabat, y otro que mencionaremos más adelante) y con la que no estamos de acuerdo. En efecto, consideramos que este manuscrito contiene el Maŷmū' fì l-filaḥa de Ibn Wāfid (pp. 1-74) y los mismos excerpta del códice anterior salidos de manos de Ibn Ḥaŷȳâŷ (pp. 74-103).

${ }^{32}$ Al-Jațāāī, M. 'A., Fahāris al-jizāna al-malakiyya, II: al-tibb wa-l-saydala wa-l-baytara wa-lhayawān wa-l-nabāt. Rabat, 1982, p. 233. 
2. Ms. número $6342^{33}$

Códice de 58 páginas en el que no se registra ningún nombre de copista y que, al igual que el 617 ŷde la Biblioteca General y Archivos de Rabat, parte de la copia escrita el 21 de muharram del año 970 (20 de septiembre de 1562), tal como puede verse en la página 57. En la última página del manuscrito se registra la fecha de elaboración de este texto: $8 \mathrm{de}$ rab $\vec{\imath}$ al-tãn $\bar{\imath}$ del año 1219, correspondiente al $17 \mathrm{de}$ julio de 1804.

$\mathrm{Al}$ igual que en el caso anterior, en el códice no aparece el nombre de ningún agrónomo andalusí pero, en el catálogo de esta Biblioteca elaborado por M. 'A. Al-Jațtābī, aparece todo él a nombre de Ibn Ḥaŷŷây. No obstante, incluye dos tratados agrícolas diferentes: el de Ibn Wāfid (pp. 2-40) y los excerpta de Ibn Haŷŷâŷy (pp. 40-58).

\section{BIBLIOTECA GENERAL DE TETUÁN}

1. Ms. número $889 / 13^{34}$

Este manuscrito de 81 páginas no se atribuye a ningún autor en el catálogo que hemos manejado pero, en la portada del mismo códice, se le cataloga como obra de Ibn Haŷŷâŷ. No posee ningún nombre de copista pero sí se registra una fecha de copia en la página 77: 15 de šawwäl de 1267, correspondiente al 13 de agosto de 1851 .

Tal como sucede en los anteriores manuscritos, pese a esta atribución del catalogador, el códice contiene, en sus páginas 1 a la 51, el Maŷmü' fī l-filāha del toledano Ibn Wāfid y, en las páginas 51 a 77, los excerpta de Ibn Haŷŷâŷ. Desde la página 78 hasta la 81 se extiende una pequeña sección titulada al-Faṣl fī dikr al-nabāt wa-l-fawäkih, que se presenta anónima y sin nombre de copista alguno.

33 Ibidem, 232-3.

${ }^{34}$ Catalogue des manuscrits de la Bibliothèque Générale de Tétouan. S.1., 1973, p. 81. 


\section{BIBLIOTECA PRIVADA DE TETUÁN}

\section{Ms. de la Colección M. 'Azīmān}

Debemos señalar que las referencias a este códice están tomadas, básicamente, de los trabajos de Millás ${ }^{35}$ ya que, pese a las numerosas gestiones personales realizadas para obtener una copia del mismo, éstas no han dado fruto. No obstante, hemos creído necesario incluirlo en este trabajo dado, por una parte, su carácter misceláneo y, por otra, su importancia como punto de referencia con otros de los aquí analizados.

Consta de un total de 136 folios y no registra nombre de copista ni tampoco está fechado aunque, para Millás, es una copia magrebí de finales del siglo XVIII o principios del siguiente ${ }^{36}$.

Lo inician unos fragmentos del resumen de la obra de al-Tignarī (fols. 2r$23 v)$. En el último de estos folios aparece la frase «wa-min kitäb Abī l-Jayn, lo que hace suponer que los folios siguientes, aunque no podemos saber con exactitud cuáles, pertenecen al agrónomo sevillano. Para Millás el texto de Abū 1-Jayr continúa hasta el 48v, afirmación no del todo exacta, ya que en ellos se encuentran pasajes de la Agricultura Nabatea, seguidos de otros de Ibn al'Awwām (fols. ?-48v) ${ }^{37}$. A continuación (fols. 48v-105v) viene el tratado de Ibn Bașșāl, para finalizar con el de Ibn Wāfid (fols. 106r-136v) ${ }^{38}$.

${ }^{35}$ Millás Vallicrosa, J. M., "Un manuscrito árabe de la obra de agricultura de lbn Wāfid», Tamuda II/1 (1954), 87-96; “Nuevos textos manuscritos de las obras geopónicas de Ibn Wāfid e Ibn Bașșal», Tamuda II/2 (1954), 339-44, y "Sobre bibliografía agronómica hispanoárabe», Al-Andalus XIX (1954), 129-42. También se ha utilizado el ya anotado trabajo de B. Attié, «L'ordre chronologique».

${ }^{36}$ Millás Vallicrosa, J. M., “Sobre bibliografía», p. 130.

${ }^{37}$ En efecto, tales folios presentan un texto que sigue muy de cerca, como se verá, las páginas 144-92 de la edición de Fez, pero no todos corresponden a Abū 1-Jayr, como pretende Millás, sino que, tras los fragmentos de Abū l-Jayr, hay otros de la Agricultura Nabatea y de la obra de Ibn al'Awwām, o bien de una sola de ellas, hecho que no podemos constatar dada la dificultad de realizar un cotejo del todo fiable cuando se trata, como en este caso, de pasajes muy alterados. $C f$. Millás Vallicrosa, J. M., "Sobre bibliografía”, 138; Attié, B., "L'ordre chronologique", 306-9 y 330.

${ }^{38}$ Al-Nahrāwī, de acuerdo con B. Attié, "L'ordre chronologique», 309. 


\section{BIBLIOTECA NACIONAL DE TÚNEZ}

\section{Ms. número $13812^{39}$}

Se trata de un breve códice que comprende dos obras de temática agrícola, ambas anónimas, con un total de 44 folios. Su copista fue Ahmad b. 'Umar alȘayd al-Manārī al-Tūnisī quien la realizó hacia mediados del siglo XVII en Túnez, según se lee en el folio 1 r.

La primera de las obras (fols. 1r-30r), hace unos años publicada, lleva por título Kitāb fī Tart ı̉b awqāt al-girāsa wa-l-magrūsāt y su anónimo autor (ss. X$\mathrm{XI})$ es considerado el primero de los agrónomos andalusíes ${ }^{40}$.

Los restantes folios (30v-44r) hemos podido comprobar que contienen algunos fragmentos de la obra de Ibn Wāfid y que en ellos no se cita a ningún autor.

\section{BIBLIOTECA DE LA REAL ACADEMIA DE LA HISTORIA DE MADRID}

\section{Ms. número XXX de la Colección Gayangos}

Dicho códice, con un total de 143 folios, no presenta fecha de copia ni nombre de copista, aunque sí notas de posesión, en primer lugar de Sulaymān b. Aḥmad al-Qaštānī, fechadas en el año 1160/1747, a las que siguen otras de fray Josef Antonio Banqueri quien, posiblemente, compraría el manuscrito al anterior.

Contiene tres tratados, todos de materia agrícola, aunque sólo los dos últimos son andalusíes ${ }^{41}$. La segunda obra, Taqyīd min dīwān al-filāha li-Ibn Faddāl (fols. 100v-141r), se trata de un compendio del Kitäb al-Qasd wa-lbayān de Ibn Bașșāl realizado, posiblemente, a partir del original del mismo y no del texto resumido que conocemos. Hay varios elementos que nos inclinan a pensar en ello: en el capítulo V se incluye un texto (fol. 119v, 1. 13-fol. 120r, 1. 4) que no aparece en la edición de Millás y 'Azīmān; por otra parte, en el

\footnotetext{
${ }^{39}$ Procede de los antiguos fondos manuscritos de la Biblioteca Zaytūna de Túnez, donde tenía el n. ${ }^{\circ} 5298$.

${ }^{40}$ Cf. Kitāb fī Tartī b awqāt al-girāsa wa-l-magrūsāt. Un tratado agrícola andalusí anónimo, ed., trad. y estudio, A. C. López y López. Granada, 1990.

${ }^{41}$ El primero, identificado con la traducción árabe de la obra de Vindanio Anatolio de Beritos, Kitāb Filāhat al-ard, ha sido publicado por M. C. Vázquez de Benito, El manuscrito número XXX de la Colección Gayangos (folios 1-98). Madrid-Barcelona, 1974.
} 
capítulo XII hay un epígrafe dedicado a la pimienta negra que es totalmente diferente al expuesto en la citada edición.

El tercero y último de los textos agrícolas que componen este misceláneo, titulado Taqyīd äjar min gayr kitāb Ibn Faddāl, es de Ibn Bașșāl, cuyo nombre, igual que en el tratado anterior, presenta una de las variantes con las que se conoce al agrónomo toledano ${ }^{42}$.

\section{BIBLIOTECA NACIONAL DE FRANCIA}

\section{Ms. número $4764^{43}$}

El nombre del único copista del códice, Muḥammad b. Aḥmad al-Magribī alFāsī, aparece en el último folio del mismo (179v), junto con la fecha de la copia: 28 de ramaḍ̄n del año 1038 (22 de mayo de 1629).

Inicia el manuscrito (fols. 1v-47r) la obra al-Mujtār min mustahsan al-aš 'ār, atribuida a Abū 'Abd Allāh Muhammad b. al-Ḥusayn ${ }^{44}$. A continuación (fols. 47r64r) viene otra copia del texto del Kitäb fī Tart ı̌b awqāt al-girāsa wa-l-magrūsāt, del ya citado Anónimo andalusí ${ }^{45}$. Los folios 64r-151v contienen parte del Kitāb al-Filāha de Abū 1-Jayr al-Šaŷŷār al-Išbīlī, como figura en el primero de los citados folios $^{46}$, siendo éste el único manuscrito en el que aparecen tales datos.

Siguen (fols. 151v-160v) unos pasajes alterạdos de la obra de Ibn Wāfid y, en los folios 160v-161r, aparece un breve fragmento de una obra titulada Kitāb al-Fallaḥin, como reza en el último folio mencionado. Los siguientes (161r-162v) están extraídos del tratado de Ibn Bașșāl y, tras él (fols. 162v-175v), aparece el calendario de Abū l-'Abbās Aḥmad b. Muḥammad b. al-Bannā', como figura en el manuscrito ${ }^{47}$.

\footnotetext{
${ }^{42}$ Este breve fragmento agrícola ha sido editado y traducido por M. A. Navarro García, "Un nuevo texto agrícola andalusí", CNA II, Madrid, (1992), 155-69.

${ }^{43}$ Vajda, G., Index général des manuscrits arabes musulmans de la Bibliothèque Nationale de Paris. Paris, 1953, p. 342.

${ }^{44} C f$. Attié, B., "Les manuscrits agricoles", 252-3, donde se describe someramente el contenido de esta obra.

${ }^{45}$ Para B. Attié, quien no conocía la copia tunecina, este autor tampoco es musulmán, igual que al-Nahrāwī. Cf. Attié, B., "L'ordre chronologique», 317-21.

46 Abū l-Jayr, Kitäb al-Filăha. Tratado de agricultura, introd., ed., trad. e índices por J. M. Carabaza. Madrid, 1991.

${ }^{47}$ Finaliza el códice con una corta narración (fols. 176r-179v), anónima, de carácter mágico.
} 
2. Ms. número $5013^{48}$

Son dos los copistas que elaboran este códice, pero no conocemos el nombre de ninguno de ellos: el primero escribe los folios $1 \mathrm{v}$ al $71 \mathrm{r}$ y el segundo los folios $72 \mathrm{r}$ al 161v. No obstante, sí aparece la fecha en que la copia fue realizada: 21 de muharram del año 970, es decir, 20 de septiembre de 1562. Como podemos observar, es la fecha primera que registran tanto los manuscritos 617 ŷ y $1410 \mathrm{D}$ de la Biblioteca General y Archivos de Rabat como el número 6342 de la Biblioteca Real de Rabat, por lo que todos parten sin duda de este códice parisino.

$\mathrm{Al}$ aparecer el nombre de Ibn Haŷŷâŷ en el folio 71r como autor de la obra, en el catálogo ya anotado se asigna todo el texto a este agrónomo sevillano, pese a que claramente los folios $72 \mathrm{r}$ al $161 \mathrm{v}$ contienen el tratado agrícola de Ibn Bașsāl. En cuanto a la autoría de los folios 1v a 71r, J. M. Millás Vallicrosa opina que del $1 \mathrm{v}$ al $47 \mathrm{r}$ se extiende la obra agrícola de Ibn Wāfid, y que los folios restantes pertenecen a Ibn Haŷŷāy $\hat{y}^{49}$. Por su parte, B. Attié, basándose en los explicit de los manuscritos 1550 de la Biblioteca Nacional de Argel (ya visto) y 5754 de la Biblioteca Nacional de Francia (del que hablaremos a continuación), atribuye a un tal Abū l-Qāsim b. 'Abbās al-Nahrāwī la redacción de los folios 1v a $47 r$, en tanto que los folios $47 r$ al 71 r pertenecen para él a Ibn Haŷȳây $\hat{y}^{50}$. Los editores jordanos de $a l-M u q n i$ ', que utilizan este códice parisino, mantienen que toda la primera parte del texto, hasta el folio $71 \mathrm{r}$, es obra de este último agrónomo sevillano, pero nosotros estamos de acuerdo con lo defendido por J. M. Millás.

\section{Ms. número $5754^{51}$}

Si bien este códice consta de 186 folios, no todos ellos se destinan al tema agronómico, pues éste únicamente abarca de los folios $152 \mathrm{v}$ al $186 \mathrm{r}^{52}$. En dos ocasiones (fols. 151r y 186r) encontramos el nombre del copista y la fecha de

48 Vajda, G., Index, p. 342.

49 Millás Vallicrosa, J. M., «Nuevos textos”, 340-3.

50 Attié, B., "Les manuscrits agricoles", 243 y 256-9.

51 Vajda, G., Index, p. 342.

52 Concretamente, los folios $2 \mathrm{v}$ al $69 \mathrm{v}$ contienen una obra de tema histórico; los folios 70r a 72r se hallan en blanco; del $72 \mathrm{v}$ al $151 \mathrm{r}$ se extiende la llamada al-Rihla al-Gazzäliyya, obra de índole geográfica perteneciente a Aḥmad b. al-Mahdī al-Gazzāl al-Fāsī y, finalmente, los folios 151v y 152r están en blanco. 
redacción de la copia: Muḥammad al-Ṣāliḥ b. Aḥmad Zarrūq b. Muhammad al'Antarī y finales de raŷab de 1192, equivalente a finales de agosto de 1778.

También en dos folios del texto, concretamente el 176v y el final del códice, hallamos el nombre del autor: Abū l-Qāsim b. 'Abbās al-Nahrāwī que, como ya hemos indicado, resta en el anonimato para B. Attié pero que, con mayor acierto en nuestra opinión, es identificado con el médico cordobés Abū l-Qāsim Jalaf b. 'Abbās al-Zahrāwī (Abulcasis latino) por J. M. Millás Vallicrosa y por E. García Gómez $^{53}$. Igualmente se añade en ambas ocasiones el título de la obra: Kitāb alFilăha o Tratado de agricultura. No obstante esto, mientras que en los folios $152 \mathrm{v}$ al 176v sí se registra en efecto la obra agrícola atribuida a al-Nahrāwī por B. Attié y a Ibn Wāfid de nuestra parte, los restantes 176v a 186r no salen de las manos de al-Nahrāwī como reza en el manuscrito, sino que contienen un resumen - o extractos de éste - del tratado de agricultura de Ibn al-'Awwām, tal como afirma el profesor B. Attié ${ }^{54}$.

Para continuar este apartado, hemos de mencionar otros dos manuscritos que, si bien no están escritos en árabe, sí que poseen el carácter misceláneo al que nos hemos referido hasta ahora y también contienen obras de agronomía andalusí: se trata del manuscrito número 10106 de la Biblioteca Nacional de Madrid, procedente del antiguo fondo de la Biblioteca Catedral de Toledo, y del códice número 93 de la colección de manuscritos españoles y portugueses de la Biblioteca Nacional de Francia. Veamos brevemente cada uno de ellos.

1.- Ms. número 10106 de la Biblioteca Nacional de Madrid.

Como J. M. Millás Vallicrosa indica ${ }^{55}$, este códice de carácter misceláneo contiene dos textos en castellano de distinto tema y con numeración independiente, escritos por diferentes manos a principios del siglo $\mathrm{XV}$ : el primero de ellos, que ocupa 16 folios, versa sobre cuestiones de aritmética, y el segundo

53 Attié, B., "L’ordre chronologique», 321-2; García Gómez, E. "Traducciones alfonsíes”, 396; Millás Vallicrosa, J. M., "Aportaciones para el estudio de la obra agronómica de Ibn Haŷŷāŷ y de Abū l-Jayr", Al-Andalus XX (1955), p. 98, nota 3. De la misma opinión es M. Ullmann, como ya vimos en la nota . $^{\circ} 25$.

54 Attié, B., “Les manuscrits agricoles”, p. 261.

${ }^{55}$ Cf., entre otros trabajos del mismo autor, Millás Vallicrosa, J. M., "La traducción castellana del Tratado de agricultura de Ibn Wāfid", Al-Andalus VIII (1943), 282. 
comprende las traducciones castellanas de dos obras agrícolas andalusíes, las de Ibn Wāfid (fols. 1r a 16r) e Ibn Bașșāl (fols. 17r a 66r) ${ }^{56}$.

Gracias a referencias bibliográficas y a los diversos cotejos realizados, Millás sostiene ambas atribuciones pese a que ambos textos se presentan fragmentarios y anónimos, y aunque después surgieron otras opiniones sobre la autoría del primero de ellos ${ }^{57}$, creemos que ninguna ha invalidado las afirmaciones de aquel insigne profesor, por lo que esta traducción castellana viene a confirmar la autoría toledana de algunos códices puestos a nombre de al-Nahrāwī o de Ibn Haŷŷâŷy con los cuales coincide. En cuanto a la traducción castellana del tratado de Ibn Bașsāal, serviría más tarde a J. M. Millás para rellenar algunas lagunas existentes en los manuscritos árabes de dicho tratado.

2. Ms. número 93 de la colección de códices españoles y portugueses de la Biblioteca Nacional de Francia.

Según A. Morel Fatio ${ }^{58}$, este manuscrito catalán misceláneo se había redactado en el siglo XVI y contenía tres partes: 1) ochenta y dos capítulos destinados a injertos, plantío de árboles, conserva de frutas, etc. (fols. 1-30v); 2) "De agricultura Paladii", constituida por cinco libros ${ }^{59}$ (fols. 30v-62r), y 3) «De agricultura altra obra", tratado sobre plantación arbórea, cría de animales, y preparación de variados remedios (fols. 62r-130r). Casi un siglo después, W. Mettmann consideraba este manuscrito del siglo XIV o comienzos del XV, y aclaraba que la tercera parte titulada "De agricultura altra obra» contenía dos obras diferentes: el Tratado de agricultura de Ibn Wāfid (fols. 62r-111r) y un libro de dietética denominado Dela remenbrança deles viandes (fols. 111r-130r)

\footnotetext{
${ }^{56}$ Millás Vallicrosa, J. M., "La traducción castellana del Tratado de agricultura de Ibn Wāfid", AlAndalus VIII (1943), 281-332, y «La traducción castellana del Tratado de agricultura de Ibn Bașșāl”, Al-Andalus XIII (1948), 347-430.

${ }^{57}$ Como, por ejemplo, la de E. García Gómez que duda entre atribuirla a Ibn Haŷŷāŷ o a Abū lJayr. García Gómez, E., "Traducciones alfonsíes”, 394-6.

${ }^{58}$ Morel Fatio, A., Catalogue des manuscrits espagnols et des manuscrits portugais (terminé en collaboration avec M. Ch. Baudon de Mony). Paris, 1892, 32-3.

${ }^{59}$ Para A. Morel no se trata de una traducción de la obra agrícola del latino Paladio, sino de una especie de continuación de la parte primera del códice. No obstante, hay constancia de que el tratado de dicho autor latino se tradujo al catalán y, muy probablemente, esta versión sea la que se encuentra en el manuscrito que nos ocupa. $C f$. García Sánchez, E., "La traducción catalana medieval del Kitảb alAgdiya (Tratado de los alimentos) de Avenzoar", Actes del Ir Col.loqui d'Història de l'Alimentació a la Corona d'Aragó. Edat Mitjana. Lleida, 1995, 363-86.
} 
cuyo autor deja en el anonimato ${ }^{60}$. Años después, E. García Sánchez demostraba que la obra de dietética ya aludida era el Kitāb al-Agdiya de Avenzoar, y que el códice número 93 databa de finales del siglo XV o comienzos del XVI, si bien se entronca con las traducciones realizadas durante los reinados de Jaime II (12911327) y de Pedro IV el Ceremonioso (1336-1387) ${ }^{61}$.

En un estudio posterior ya anotado, confirmamos que la redacción primera de esta versión catalana databa de la época de Pedro IV, y que el autor de la obra traducida es el toledano Ibn Wāfid (pese a que en el códice se muestra anónima), quien fue bien conocido y apreciado por los traductores de la Corona de Aragón ya que, además de su obra agrícola, vertieron al catalán su Kitāb al-Adwiya almufrad $a^{62}$. Por consiguiente, esta versión catalana reafirma la paternidad de Ibn Wāfid con respecto a los códices que, en ocasiones, se atribuyen a al-Nahrāwī, en otras a Ibn Hạŷȳây (cuando en realidad se trata del texto de Ibn Wāfid seguido de los excerpta de aquel agrónomo sevillano), y en otras se dejan en el anonimato.

Aunque no sabemos de qué manuscritos misceláneos concretos se trata, no podemos finalizar este apartado de nuestro trabajo sin hablar de dos ediciones de textos agrícolas andalusíes realizadas en el Norte de África, a primeros del presente siglo. Ninguna de ellas revela el manuscrito del que parte, pero ambas son de carácter misceláneo, como los códices ya examinados.

\section{Edición de Fez}

Nos encontramos ante una de las ediciones de textos agrícolas andalusíes que más ha inducido a errores de autorías ya que, por una parte, está atribuida a Abū 1-Jayr cuando, realmente, es una obra miscelánea ${ }^{63}$. Por otra, se publicó relativamente temprano (1357/1938), en un momento en el cual Millás Vallicrosa había iniciado los estudios sobre agronomía andalusí, basándose únicamente en la traducción castellana de Ibn Wāfid, ya mencionada, de la que se desconocía el

60 Mettmann, W., "Eine Übersetzung des "Kompendiums" von Ibn Wāfid und andere altkatalanische Texte über die Landwirtschaft”, Romanische Forschungen 92 Bd. (1980), 350-3.

${ }^{61}$ García Sánchez, E., "La traducción catalana”, 365-6.

62 Ibn Wāfid, El "Libre de les medicines particulars", versión catalana trescentista del texto árabe del "Tratado de los medicamentos simples", ed. L. Faraudo de Saint-Germain, Barcelona, 1943.

${ }^{63}$ Abū l-Jayr al-Andalusī, Kitāb al-Filăha, ed. Sīdī al-Tuhāmī al-Nāṣirī al-Ŷa ‘farī. Fez, $1357 \mathrm{H}$. 
original árabe, y que resultó ser uno de los fragmentos contenidos en esta edición encontrada por E. García Gómez ${ }^{64}$ en Marruecos.

Tiene 217 páginas, precedidas de unas palabras introductorias del editor y otras del corrector de la edición, Muḥammad b. 'Abd al-Malik al-Rasmūkī, sin paginar, seguidas de un prólogo. No se indica la procedencia del manuscrito, ni nombre del copista. Contiene los siguientes textos, todos ellos incompletos:

Sobre la autoría del ya citado prólogo anónimo (pp. alif-tâ’) se han barajado distintas opiniones. E. García Gómez ${ }^{65}$ cree que es obra del mismo editor, sobre lo que J. M. Millás no se pronuncia de forma explícita, aunque se puede sobreentender que lo corrobora ${ }^{66}$. Otra hipótesis, con la que nos identificamos, es la propuesta por B. Attie $e^{67}$, para quien este prólogo se debe a al-Tignarī o al autor del resumen que se hizo de su tratado, Ibn Hamdūn al-Išbīlī, ya que estas páginas se corresponden fielmente con el inicio del Kitāb Zuhrat al-bustān del agrónomo granadino.

A continuación se reproduce de nuevo la portada de la edición, como si realmente se iniciara aquí la obra, y tras ella se inserta el tratado de Ibn Wāfid (pp. 2-82). Las dos páginas siguientes (83-84), truncadas y con un explicit a nombre de Abū l-Jayr, son de autor desconocido, de acuerdo con E. García Gómez ${ }^{68}$, y de Abū 1-Jayr o, más bien, de Ibn Hayŷyāŷ, para B. Attié ${ }^{69}$. Sin embargo, son realmente de Abū l-Jayr como afirma J. M. Carabaza ${ }^{70}$. A continuación (pp. 85144), tras una nueva basmala y tasliya, aparecen unos extensos pasajes del resumen de la obra de al-Țignarī, en lo que encontramos unanimidad de opiniones.

Tras la indicación «wa-min kitāb Abī l-Jayn» de la página $144^{71}$, que debió ser el motivo de la atribución del códice completo al agrónomo sevillano, se inician unos pasajes que, efectivamente, corresponden al mismo (pp. 144-74), como intuyó J. M. Millás y más tarde confirmaron B. Attié y otros.

64 García Gómez, E., "Sobre agricultura arábigoandaluza. Cuestiones biobibliográficas», AlAndalus X (1945), 127-46.

65 Ibidem, p. 127.

${ }^{66}$ Millás Vallicrosa, J. M., "Sobre bibliografía”, 130.

${ }^{67}$ Attié, B., "L'ordre chronologique", 311.

${ }^{68}$ García Gómez, E., "Sobre agricultura», 132. Dicho profesor no pudo llegar a delimitar en este trabajo las distintas autorías que contiene el texto de Fez, ya que cuando éste se publicó solamente se conocía, además del tratado de Ibn al-‘Awwām, la traducción castellana del de Ibn Wāfid.

${ }^{69}$ Attié, B., "L'ordre chronologique", 307 y 312.

${ }^{70}$ Abū l-Jayr, Kitäb al-Filäha, 28.

71 Dicha frase, como se ha visto, también se encuentra en el folio $23 \mathrm{v}$ del misceláneo de $\mathrm{M}$. 'Azīmān. 
En la página 174, y conservando una aparente continuidad con el texto precedente, figura la indicación "min kitāb al-Filäha al-Nabatiyya", con un explicit en la página 192 en donde se constata el final del contenido de esta obra. Estas páginas contienen fragmentos sueltos y muy resumidos de la Agricultura Nabatea, que bien podrían estar tomados de otros autores andalusíes - caso de al-Ṭignarī o Ibn al-'Awwām - que utilizan a menudo dicha fuente. Para J. M. Millás ${ }^{72}$, estas páginas son también de Abū l-Jayr.

Las páginas comprendidas desde la 193 -que presenta unos cuadros con las equivalencias de los nombres de los meses rumíes, siriacos y coptos- hasta la 201 se deben a M. Rasmūkī y contienen los índices del libro. Les siguen otras (202-12) en las que se incluye una fe de erratas.

Por último (pp. 213-17), a modo de apéndice, posiblemente del editor, se recogen unas aplicaciones o normas prácticas extraídas de diversos textos agrícolas andalusíes o, más concretamente, sevillanos, como denotan sus nisba(s): "Azhār al-bustān wa-nuzhat al-adhān de al-Išbīlī» (es decir, de al-Ṭignarī), "Kitāb barābir (sic) al-"Awwām al-Išbīlī fī filạha", "al-Dīwān fī filăhat al-arḍ wa-lḩayawān de Abū l-Ḥusayn Yạ̣yà Ibn Muhammad al-'Awwām al-Ḥaḍrāmī alIšbilī", autor este último que nos es desconocido, aunque hay algunos elementos en su cadena onomástica que coinciden con los de Ibn al-‘Awwām.

\section{Edición de Túnez}

Esta edición carece de fecha determinada, pero creemos que se elaboraría prácticamente en el mismo período que la anterior ${ }^{73}$. El autor de la obra, tal como aparece en la portada, es Ibn al-Șawwām al-Andalusī, nombre que después viene a completarse en la página 3 del libro: Abū 'Abd Allāh Muhammad Ibn alṢawwām al-Andalusī. El título que se registra en la portada es Kitāb Mujtașar alfilāha al-ifr íqiyya, pero en el interior de la obra (pp. 3 y 6) se cambia por el de Kitāb Mujtașar al-filāha 'alà l-kamāl wa-l-tamām. El editor es el šayj 'Alī alŠannūfi, sabio de la Mezquita al-Zaytūna de Túnez, quien añade un prólogo a su edición y anota algunos términos de la obra agrícola.

Como puede observarse, el nombre del autor está muy alterado (fruto de los múltiples pasos seguidos en la transmisión del texto) ya que es una mezcla de la

\footnotetext{
72 Millás Vallicrosa, J. M., "Sobre bibliografía”, 139-40.

${ }^{73} C f$., con respecto a esta edición tunecina, Carabaza Bravo, J. M., "Un compendio tunecino de geoponimia andalusí", Boletín de la Asociación Española de Orientalistas XXX (1994), 309-18, y XXXI (1995), 219-29.
} 
kunya e ism tanto de Ibn Bașșāl como de al-Ṭignarī, y del nasab deformado de Ibn al- 'Awwām. A ello se unió la atribución errónea de Henri Pérès quien ve en este nombre un alias (junto con el de Abū l-Qāsim b. 'Abbās al-Nahrāwī) de Ibn Haŷŷâŷ al-Išbīilīit . Sin duda alguna, le llevó a esta conclusión el hecho de que el contenido de esta edición tunecina era muy similar a los códices puestos a nombre de Ibn Haŷŷâŷy. Sin embargo, las similitudes existentes corresponden a los folios pertenecientes en dichos códices a Ibn Wāfid y no a Ibn Haŷȳây $\hat{y}^{75}$, por lo que estamos ante otra copia más resumida y alterada del Maŷmū' fì l-filāha del agrónomo toledano ${ }^{76}$.

A esta copia, que abarca las páginas 6 a 51 de la edición tunecina, le sigue un capítulo final (pp. 51-56) a modo de calendario agrícola. Aunque pudiera pensarse que sigue el texto de Ibn Wāfid que también contiene un calendario (con lo cual la obra hubiera perdido su carácter misceláneo), nos encontramos con que las coincidencias intertextuales prácticamente desaparecen. Una vez cotejado dicho calendario con las obras agrícolas andalusíes, observamos que no parte de ninguna de ellas. Tampoco coincide con otros textos agrícolas ni con los calendarios conocidos, por lo que llegamos a la conclusión de que este capítulo toma sus datos de una obra que no ha llegado hasta nosotros o que resta aún inédita y que, probablemente, corresponde al mismo entorno geográfico y cronológico que la edición que nos ocupa.

En el siguiente cuadro resumimos todo lo expuesto en este apartado, para después comentar algunos de los datos más significativos que de él se derivan.

\footnotetext{
${ }^{74}$ Abou' l-Khayr Ach-Chadjdjâr al-Ichbîlî, Kitâb al-Filâh'a ou Le Livre de la Culture, notice et extraits trad. Par A. Chérbonneau, éclaircissements par H. Pérès. Argel, 1946, 9-10. Tanto J. M. Millás como B. Attié consideran erróneas las palabras de H. Pérès: Millás, J. M., "Aportaciones", p. 98; Attié, B., "Les manuscrits agricoles", 256-7.

75 Carabaza Bravo, J. M., "Un compendio (I)», 313-8 y "Un compendio (II)», 219-26.

${ }^{76}$ Se desvincula, por lo tanto, este texto del tratado de agricultura de Ibn al- A Awwām, pese a que B. Attié opina que es un extracto de un resumen de la obra de este autor sevillano. Attié, B., "L'ordre chronologique», 331 .
} 


\begin{tabular}{|c|c|c|c|c|c|c|c|c|}
\hline $\begin{array}{l}\text { AUTORES } \\
\text { MSS. }\end{array}$ & $\begin{array}{l}\text { ANÓNIMO } \\
\text { ANDALUSÍ }\end{array}$ & $\begin{array}{c}\text { IBN } \\
\text { WĀFID }\end{array}$ & $\begin{array}{c}\text { IBN } \\
\text { HִAŶŶ̀̄ }\end{array}$ & $\begin{array}{c}\text { IBN } \\
\text { BAȘṢāL }\end{array}$ & $\begin{array}{c}\text { ABŪ } \\
\text { L-JAYR }\end{array}$ & $\begin{array}{c}\text { Al- } \\
\text { ṬIGNARI }\end{array}$ & $\begin{array}{l}\text { IBN AL- } \\
\text { 'AWWĀM }\end{array}$ & $\begin{array}{l}\text { FECHAS } \\
\text { DE COPIA }\end{array}$ \\
\hline 1550 B.N. Argel & & $\begin{array}{l}154 \mathrm{v}- \\
180 \mathrm{v}\end{array}$ & & & & & $\begin{array}{l}180 v- \\
193 v\end{array}$ & $1782-3$ \\
\hline $\begin{array}{c}617 \text { ŷ B.G. y A. } \\
\text { Rabat }\end{array}$ & & $414-478$ & $478-510$ & $270-413$ & & $1-269$ & & 1862 \\
\hline $\begin{array}{c}1410 \text { D B.G. y A. } \\
\text { Rabat }\end{array}$ & & $\begin{array}{l}157 \mathrm{r}- \\
194 \mathrm{r}\end{array}$ & $194 r-216 r$ & $1 v-98 r$ & $\begin{array}{l}130 v- \\
133 v\end{array}$ & $105 v-130 v$ & $\begin{array}{l}140 \mathrm{r}- \\
154 \mathrm{v}\end{array}$ & 1889 \\
\hline 69 B.R. Rabat & & $1-74$ & $74-103$ & & & & & 1848 \\
\hline $\begin{array}{c}\text { 6342 B.R. } \\
\text { Rabat }\end{array}$ & & $2-40$ & $40-58$ & & & & & 1804 \\
\hline $\begin{array}{c}\text { B.P. Tetuán } \\
\text { (‘Azīmān) }\end{array}$ & & $\begin{array}{l}106 \mathrm{r}- \\
136 \mathrm{v}\end{array}$ & & $\begin{array}{l}48 v- \\
105 v\end{array}$ & $23 \mathrm{v}-?$ & $2 r-23 v$ & $?-48 v$ & XVIII-XIX? \\
\hline $\begin{array}{c}\text { 889/13 B.G. } \\
\text { Tetuán }\end{array}$ & & $1-51$ & $51-77$ & & ، & & & 1851 \\
\hline $\begin{array}{l}13812 \text { B.N. } \\
\text { Túnez }\end{array}$ & $1 r-30 r$ & $30 v-44 r$ & & & & & & XVII \\
\hline $\begin{array}{c}\text { 30 BRAH } \\
\text { (Gayangos) } \\
\text { Madrid }\end{array}$ & & & & $\begin{array}{l}100 v- \\
143 r\end{array}$ & & & & XVIII? \\
\hline $\begin{array}{c}4764 \text { B.N. } \\
\text { Francia }\end{array}$ & $47 r-64 r$ & $\begin{array}{l}151 \mathrm{v}- \\
160 \mathrm{v}\end{array}$ & & $\begin{array}{l}161 \mathrm{r}- \\
162 \mathrm{v}\end{array}$ & $\begin{array}{l}64 \mathrm{r}- \\
151 \mathrm{v}\end{array}$ & & & 1629 \\
\hline $\begin{array}{c}5013 \text { B.N. } \\
\text { Francia }\end{array}$ & & $1 v-47 r$ & $47 r-71 r$ & $72 r-161 v$ & & & & 1562 \\
\hline $\begin{array}{c}5754 \text { B.N. } \\
\text { Francia }\end{array}$ & & $\begin{array}{l}152 \mathrm{v}- \\
176 \mathrm{v}\end{array}$ & & & & & $\begin{array}{l}176 v- \\
186 r\end{array}$ & 1778 \\
\hline
\end{tabular}




\section{COMENTARIO}

A la vista del anterior cuadro, lo primero que nos llama la atención son las fechas de copia de los distintos códices misceláneos. Estas son, en su mayoría, muy tardías, pues tenemos, frente a una sola copia del siglo XVI y dos del XVII, cuatro códices de probable adscripción al siglo XVIII (de ellos dos pertenecen con seguridad a dicho siglo), y cinco del XIX. Incluso, hemos de tener en cuenta que las dos ediciones magrebíes analizadas están elaboradas en la primera mitad del presente siglo. Además de este hecho, también resulta manifiesto que la copia que presenta un carácter misceláneo más acentuado es, justamente, el códice más moderno ya que data del año 1889. No obstante, no podemos deducir que el tiempo sea un factor determinante del fenómeno misceláneo pues, desde la copia más antigua (que contiene tres textos diferentes), la fusión de obras agrícolas es constante a lo largo de todos los manuscritos, dada la finalidad práctica que poseían.

Un tercer elemento que hay que destacar en el cuadro presentado es el número de ocasiones en que aparece cada agrónomo andalusí. Indiscutiblemente, el autor más citado es el que hemos identificado con Ibn Wāfid (al-Nahrāwī/al-Zahrāwī en algunos códices e Ibn Hayŷyāŷ en otros), al que siguen en número de citas el sevillano Ibn Hậŷāŷy y el agrónomo toledano Ibn Bașạāl. Con respecto a los dos primeros, es muy llamativo el que casi siempre aparezcan sus tratados unidos y en la misma disposición, es decir, la obra agrícola completa de Ibn Wāfid seguida de los excerpta de Ibn Ḥaŷŷây. Únicamente no se da este caso cuando sólo se recogen fragmentos del tratado del autor toledano (manuscritos de M. 'Azīmān, 13812 de Túnez y 4764 de París), o bien cuando la obra se atribuye a al-Nahrāwī (códices 1550 de Argel y 5754 de París). Una explicación posible a este hecho es el contenido de ambos textos: las referencias que Ibn Wāfid hace a cultivos básicos de la zona mediterránea, como son el olivo, la vid y la higuera, son escuetas y relativas más al dominio mágico y de economía rural que al propiamente agrícola, en tanto que los temas abordados por Ibn Haŷŷâŷ, con respecto a estos mismos árboles, son plenamente de carácter práctico y, por tanto, vienen a completar los datos ofrecidos por el primero de ambos geóponos.

Dos cuestiones - también referentes a ambos agrónomos- a las que aún no encontramos respuesta son, en primer lugar, la relativa a la pérdida del nombre de Ibn Wāfid y, en segundo, la exclusiva conservación de determinados fragmentos de la obra de Ibn Haŷyyâŷ. El tratado del primer autor, como ya hemos indicado, es el que más veces se registra en los códices misceláneos, posee dos traducciones medievales al castellano y al catalán, fue utilizado por Gabriel Alonso de Herrera 
en el siglo XVI, y es parte fundamental y casi única de la edición de Túnez ya aludida. Por tanto, estamos ante una obra muy apreciada y de gran difusión tanto en nuestra Península como en el Norte de África, pero el nombre de Ibn Wāfid no es citado ni en los códices que poseemos y ni tan siquiera por Ibn al-'Awwām quien, en su Kitāb al-Filăha, nombra a los geóponos andalusíes que le precedieron. En cuanto al tratado de Ibn Haŷŷây, sorprende que sólo se conozcan algunos de sus fragmentos cuando, a finales del siglo XII-primeros del XIII, Ibn al'Awwām maneja la obra completa y le concede un lugar de clara preferencia entre los restantes tratados de la escuela agronómica andalusí.

El tercer autor más citado, como ya hemos dicho, es Ibn Bașșāl. Aunque en casi todos los manuscritos misceláneos vistos se recoge el resumen de la obra de este autor, lo cual muestra la difusión que dicho resumen tuvo en el Magreb, el texto original completo pasó relativamente pronto a zonas más orientales del mundo arabo-islámico, sin que quedasen huellas de él en la parte occidental después del siglo XIV. Ya hemos señalado las citas de la obra completa que realiza el autor del Miftāh al-rāha li-ahl al-filāha, a las cuales podrían añadirse las del soberano yemení al-Mālik al-Afụal (s. XIV) quien, en su Bugyat al-fallāh ìn fīlašŷār al-muțmira wa-l-rayạ̣n inn, nombra a Ibn Bașșāl en variadas ocasiones como, por ejemplo, en el cultivo del arroz y otros cereales, cultivo del azafrán y poda arbórea $^{77}$, y las del enciclopedista egipcio al-Watwat (s. XIV) en su obra Mabāhiy al-fikar fī manāhiŷ al- 'ibar ${ }^{78}$.

$\mathrm{Al}$ igual que pasó con Ibn Bașsāl, el tratado agrícola de Ibn al-'Awwām fue conocido en Oriente, como lo confirma la cita que de su libro hace el autor sirio 'Abd al-Ganī al-Nābulusī (m. 1731) en el Kitāb 'Alam al-malăha fí 'ilm al-filāḥa, referida a cómo obtener espárragos sin cultivarlos ${ }^{79}$.

A través de todos los casos examinados, podemos afirmar que los tratados agrícolas andalusíes no sólo fueron apreciados en nuestra Península sino fuera de ella, desde la Baja Edad Media hasta el siglo XVIII, e incluso el hecho de que las copias que han llegado hasta nosotros sean, en su mayor parte, de los siglos XVIII y XIX demuestra, a todas luces, que tuvieron una repercusión duradera en el Norte de África. Si tenemos en cuenta que, durante los siglos de dominación otomana, las cuestiones agrícolas quedaron - tanto en el Occidente como en el Oriente islámico- enmarcadas en obras de carácter económico, no es extraño que se volvieran los ojos a los tratados agronómicos hispanoárabes para dar un impulso

77 Meyerhof, M., "Sur un traité d'agriculture composé par un sultan yéménite du XIVe siècle», Bulletin de l'Institut d'Egypte XXVI (1943-44), 53, 58 y 62.

${ }^{78}$ Ibn Bașsāal, Libro de agricultura, p. XXXI.

${ }^{79}$ Al-Nābulusī, 'Abd al-Ganī, Kitäb 'Alam al-malăha fí 'ilm al-filaḥa. Dimašq, 1299 H., p. 133. 
a la actividad propiamente agrícola, en unos momentos en los que no se establecían nuevas directrices para el cultivo de los campos.

La misma proyección de este aspecto eminentemente práctico propio de los textos agrícolas andalusíes la encontramos, en la época de la Ilustración española, en las palabras que Campomanes dirige al editor y traductor de Ibn al-'Awwām, José A. Banqueri, en las que dice: “Considerando yo el grande y principal influxo que tiene la agricultura en la felicidad del estado, creí que no podia hacer mayor servicio al público que ofrecerle la traduccion castellana de un códice de argumento tan importante, de que pudiesen aprovecharse nuestros agricultores ${ }^{80}$. Así pues, la influencia de la escuela agronómica andalusí perduró claramente en nuestro país hasta el siglo pasado, y posteriormente en el Norte de África, diríamos que en mayor grado que en la época y entorno en que aquélla produjo sus mejores escritos.

\section{RESUMEN}

La mayoría de los tratados agrícolas andalusíes se encuentran en códices de carácter misceláneo que, en gran parte, se atribuyen a un solo autor. Esto ha originado una serie de falsas autorías cuyas causas analizamos en este trabajo. Tras esto, procedemos a un breve estudio de los distintos manuscritos misceláneos, incidiendo en el hecho de las diferentes atribuciones de que han sido objeto y tratando de delimitar cada una de ellas. Este estudio se resume a continuación en un cuadro y, para finalizar, comentamos los datos más significativos que se desprenden de toda la información anterior, añadiendo algunas referencias a la proyección que tuvieron las obras de la escuela agronómica andalusí.

\section{ABSTRACT}

The majority of treatises on agriculture in al-Andalus can be found in miscellaneous codexes which are mainly attributed to only one author, which has brought about a number of false attributions of authorship we will analyse in this research. We then make a brief study of the different miscellaneous manuscripts, studying the different attributions to which they have been object more in detail so as to attempt to mark the boundaries of each one. This study is summarized in a table. Finally, we discuss the more significant data from the previous information, adding some references about the influence the works of the agronomical school of al-Andalus had.

${ }^{80}$ Ibn al-'Awwām, Libro de agricultura, p. 23 del discurso preliminar de Campomanes. 